\title{
Natureza e origem da Bibliografia: uma perspectiva disciplinar para contemporaneidade ${ }^{\mathbf{1}}$
}

\author{
Nature and origin of Bibliography: disciplinary perspective to contemporaneity
}

\author{
Fiammetta Sabba \\ Doutora em Ciências Bibliográficas, Arquivísticas, Documentárias e para Restauro e Conservação dos Bens \\ Bibliotecários e Arquivísticos - Universidade de Udine. \\ Professora Associada do Departamento de Bens Culturais da Universidade de Bolonha - UNIBO. \\ E-mail: fiammetta.sabba@unibo.it
}

\begin{abstract}
Resumo
O trabalho propõe o estudo da Bibliotheca Universalis de Conrad Gesner através da tipologia de fontes de informação utilizadas pelo autor em sua composição e de sua representatividade bibliográfica em relação à cultura escrita disponível na época. Com base nisso, propõe medir o grau de 'universalidade' da obra na perspectiva da meta desejada e dos instrumentos a sua disposição. Para isso, se elabora um percurso de revisão das fontes utilizadas por Gesner, que variam entre catálogos editoriais, catálogos de bibliotecas e, ainda, bibliografias propriamente ditas, fontes obtidas, na maioria das vezes, ao longo de viagens realizadas pelo autor. Se destaca assim, na reconstituição desse percurso de pesquisa de Gesner, a atualidade de seu projeto bibliográfico, fundamentado no princípio de registrar o patrimônio escrito, de classificá-lo e identificar aquilo que ainda precisava se tornar público. Desenvolve-se, ainda, uma discussão que visa mostrar afinidades e paralelismos entre as necessidades de uma construção 'semântica' da informação nos nossos tempos e a atualidade do Método Gesneriano para tanto.
\end{abstract}

Palavras-chave: Bibliografia - História e Teoria. Conrad Gesner (1516-1565). Bibliotheca Universalis (1545). Método Gesneriano. Pandectae (1548-1549).

\begin{abstract}
The paper proposes the study of Bibliotheca Universalis of Conrad Gessner through the typology of information sources used by the author in its composition and its bibliographical representation in relation to written culture available at the time. On that basis, the paper proposes to measure the degree of 'universality' of the work in view of the desired goal and the instruments at their disposal. For this, it prepares a route review of the sources used by Gesner ranging from publishing catalogs, library catalogs, and also actual references, sources obtained, most often over trips made by the author. Stands thus in the reconstruction of this Gesner route research, the relevance of his bibliographic project, based on the principle of recording the written heritage, to classify it and identify what still needed to be made public. It develops also a discussion that aims to show affinities and parallels between the needs of a 'semantic' construction information in our times and the actuality of Gesnerian Method therefore.
\end{abstract}

Keywords: Bibliography - History and Theory. Conrad Gesner (1516-1565). Bibliotheca Universalis (1545). Gesnerian Method. Pandectae (1548-1549).

\footnotetext{
${ }^{1}$ Tradução de Giulia Crippa. Revisão de André Vieira de Freitas Araujo.

InCID: R. Ci. Inf. e Doc., Ribeirão Preto, v. 7, n. esp., p. 65-98, ago. 2016. 


\section{Introdução}

Essa contribuição é a elaboração por escrito da "Conferência de Encerramento" que ministrei no dia 4 de dezembro de 2015 na Biblioteca da Faculdade de Economia e Administração da Universidade de São Paulo (FEA-USP), em ocasião do II Seminário Internacional “A Arte da Bibliografia: História, Natureza e Relações (Inter)Disciplinares”, realizado junto ao Programa de Pós Graduação em Ciência da Informação da Escola de Comunicações e Arte da Universidade de São Paulo (ECA-USP).

No título do Seminário foi utilizado o termo 'Arte' em relação à Bibliografia; trata-se de uma aproximação críptica que, porém, acabou se revelando e se esclarecendo ao longo dos dois dias do evento: 'Arte bibliográfica' enquanto técnica, mas também tecnologia e, ainda, acima de tudo, como conhecimentos, competências, sabedorias, expedientes e estratégias da Bibliografia em relação à tradição escrita - sígnica e simbólica - para uma interpretação histórica e, ao mesmo tempo, futurística do mundo da informação.

O conceito de 'informação' é, por sua vez, complexo e amplo, e seu valor depende do ponto de vista das disciplinas e dos campos que o utilizam, o tratam e o analisam, tais quais os âmbitos informático, cibernético, filosófico, jornalístico, artístico, sociocultural...

Atenção deve ser reservada falando em dados como informações, isso vale sempre e tanto mais em nosso campo das 'comunicações documentárias'. Para que um dado ou grupos de dados se transformem em informação sua recepção deve, com efeito, acontecer por parte de uma estrutura já suficientemente complexa e aparelhada para recebê-los e elaborá-los. Os dados se transformam em informação, portanto, somente nas condições em que podem contribuir a elevar mais o nível de complexidade de que aquela estrutura receptora já é portadora.

A Ciência da Informação é uma disciplina interessante, rica, atual e necessária, porém não é uma ciência do ponto de vista constitutivo, pois não possui seu próprio protocolo epistemológico e metodológico que permite comparações. Ao invés disso, ela baseia-se nos resultados de outras disciplinas para compor suas teorias e para construir suas perspectivas. Isso nos induz a afirmar que essa não é uma ciência em si, mas torna-se tal na medida em que assume uma natureza transdisciplinar que lhe impõe um método não tanto de consolidação de si mesma, quanto de coesão e amálgama de outras ciências; podemos portanto definir mais corretamente a Ciência da Informação como uma ciência das comunicações. 
Essa premissa nos introduz à reflexão sobre Bibliografia, sobre seu papel como disciplina e sobre seus pressupostos conceituais enquanto 'Ciência das comunicações registradas'. De um ponto de vista bibliográfico, com efeito, nos interessa aquela informação ligada à produção literária e científica escrita. Isso, como no caso da Ciência da informação, nos obriga a uma avaliação epistemológica e a nos perguntarmos se os temas enfrentados pela Bibliografia não teriam direito de serem tratados pelos setores científicos da História e da História da Literatura, ou se as 'Disciplinas do livro e do documento' possuem verdadeiramente uma sólida tradição e razões suficientes para existirem autonomamente de um ponto de vista tanto científico quanto acadêmico.

\section{Natureza e papel disciplinar da Bibliografia}

Para entender o papel da Bibliografia é necessário antes compreender sua natureza, tanto através de sua relação com a biblioteca como conceito teórico e como sistema de gestão, bem como mediante sua relação com a História da Bibliografia e com a História das Bibliotecas.

Os termos 'biblioteca' e 'bibliografia' apresentam a mesma raiz semântica, que é aquela contida nas palavras gregas ó $\beta i \beta \lambda o \varsigma-o v$, isso é: casca, livro, e $\tau o ́$ $\beta \imath \beta \lambda i ́ o v-o v=$ papel, escrito, obra, livro; enquanto se diferenciam pela desinência diferente, originada pelas palavras $\dot{\eta} \theta \dot{\eta} \kappa \eta-\eta \varsigma$, caixa, baú, embalagem, e $\dot{\eta} \gamma \rho \alpha \varphi \dot{\eta}-\eta \varsigma$, escrita. Com a palavra latina 'bibliotheca' pelo menos até o século XVII entendia-se tanto uma 'livraria' quanto um 'catalogus', pois tratava-se de um recipiente de livros, fossem eles presentes fisicamente (ordenados nas estantes e nas prateleiras da biblioteca para serem consultados) ou presentes virtualmente (através de sua sinalização com finalidade informativa, conforme uma ordem alfabética ou sistemática, em um catálogo ou em um repertório bibliográfico).

Nessa sobreposição paradoxalmente encontra-se a essência metafísica da Bibliografia, que se ocupa, com efeito, de acolher e ordenar as conotações literárias e os elementos semânticos dos documentos gerados pelas outras disciplinas, no âmbito das quais serão sucessivamente reutilizados. A Bibliografia, portanto, consiste em uma metaestrutura, e é ela mesma uma metadisciplina que se torna ancilla e domina em relação a todas as outras categorias disciplinares: utiliza os produtos escritos no âmbito das outras disciplinas e os devolve a elas de forma organizada, para garantir sua recuperação, a permanência como sinal 
e, onde possível, sua fruição.

Para essa atividade organizadora a bibliografia utiliza 'índices' que são exatamente aqueles conotados já mencionados, enquadrados em esquemas categoriais que mediam entre as exigências explícitas, implícitas e latentes do usuário, ou dos grupos de usuários, e as ofertas informacionais documentárias. Os planos de ação são o literário-autoral (autores, obras e edições), e o semântico-conceitual (assuntos, matérias, classes, âmbitos disciplinares). Trata-se da impostação que reencontramos nos Functional Requirement for Bibliographic Records (FRBR) com os quais a International Federation of Library Associations and Institutions (IFLA) desde 1998 comprometeu-se a adequar às novas exigências dos usuários as normas catalográficas formuladas em 1961 pelos Princípios de Paris.

- Entidade 1. grupo - obra

$$
\begin{aligned}
& \text { - expressão } \\
& \text { - manifestação } \\
& \text { - item }
\end{aligned}
$$

- Entidade 2. grupo - pessoas/entidades responsáveis (na criação, realização, distribuição e gestão das entidades do primeiro grupo)

- Entidade 3. grupo

(assuntos das obras)

$$
\begin{aligned}
& \text { - conceito } \\
& \text { - objeto } \\
& \text { - evento } \\
& \text { - lugar }
\end{aligned}
$$

Os índices configuram-se dessa forma como o produto e o instrumento das atividades de mapeamento e organização da Bibliografia, e a Bibliografia pode assim ser definida também como 'Ciência das comunicações mediadas por índices'.

A Bibliografia, porém, se divide em dois ramos, um é o atual e um é o histórico, ambos com uma tarefa primária para o conhecimento: o primeiro desempenha um papel fundamental na permanência das memórias escritas, que são a garantia da civilização humana; o segundo interpreta as etapas disciplinares teóricas e evolutivas, explicando as 'naturais seleções' que aconteceram tanto para os documentos quanto para os mapas teóricos no âmago de cada época ou território cultural. Isso significa que também existe uma classificação das 
indagações bibliográficas em cronológica, geográfica, disciplinar, um pouco como acontece também para a História da literatura que, diferentemente da Bibliografia, porém vê seu campo de ação se restringir a determinadas tipologias textuais.

Da História da Bibliografia de fato desenvolveu-se, em particular no século XVIII a Historia literaria que, em seguida consolidou-se na História da Literatura da qual já acenamos, enquanto a Bibliografia tornou-se, aos poucos, em sentido metafórico, a imagem no espelho da História da Cultura, a ser entendida como o Zeitgeist do mapeamento dos conhecimentos e da estratificação do saber.

Se a biblioteca é o sistema que põe em relação esses elementos:

a) Autores (vontades intelectuais)

b) Livros (Obras + Edições: manifestações intelectuais e materiais)

c) Catálogos (conjunto de índices, esqueleto dos mapas categoriais, mediadores)

d) Usuários (exigências informacionais conscientes, recepções inconscientes de ofertas informacionais)

... E se a biblioteca é composta por esses elementos constitutivos:

a) Fundador (imprinting)

b) Possessor/gestor (pública/privada - propriedade/acesso; estatais, de entidades, de comunidades, de ordens, de associações, universitárias ...)

c) Coleções (histórica, moderna, de conservação, de consulta)

d) Finalidades (mission)

e) Usuários

f) Instrumentos (catálogos - reais, por autores, por matérias - e inventários)

g) Documentos (suportes vários)

Então no âmbito da disciplina de História das bibliotecas pode-se reconstruir tanto a história de uma instituição quanto a história do valor documentário e cultural de uma coleção, portanto indiretamente, a história de "uma cultura". Em ambos os casos, de forma específica, descreve-se sua origem e fundação, sua história, consistência, destino e uso, e contextualizase culturalmente. Mas na História das bibliotecas existem grandes dificuldades, que residem, em primeiro lugar, na relação de grande indeterminação existente entre os elementos que já vimos compor uma biblioteca. Essa distância e tamanha rigidez aumentam nas bibliotecas de conservação, nas quais as estratificações dos livros pertencentes a épocas e culturas diferentes 
Natureza e origem da Bibliografia: uma perspectiva disciplinar para contemporaneidade

entre si e da atual, desequilibram totalmente o conceito de congruência entre demanda e oferta, pois os mapas científicos e conceituais de referência e comparação são diferentes.

Em todo caso uma "História da biblioteca" deve sempre ser acompanhada por uma "História das bibliotecas": ao lado de uma análise dos acontecimentos (dos fatos que a viram protagonista) e administrativa, de fato há uma análise bibliográfico-cultural (elemento que a distingue das outras instituições com tarefas de caráter sócio-assistencial, como, por exemplo, as escolas e os hospitais). É também indispensável atuar na História das bibliotecas buscando individualizar paradigmas, modelos de referência e de valor, conforme a tipologia estudada, para poder realizar processos de comparação. Na prática isso significa se por nas condições de poder medir tanto o grau de cobertura bibliográfica (literária, científica, editorial) quanto o nível das lógicas de sua organização (catálogos, classificações, disposição física dos documentos).

Por outro lado, as bibliotecas representam de fato a única testemunha de publicitação do passado e do presente, enquanto nenhuma elaboração bibliográfica ou histórica ou literária assinala, utiliza e ainda menos espelha tudo que há nas bibliotecas e que poderia ser utilizado.

A Bibliografia é a disciplina que está na base dessas reconstruções históricas, fazendo emergir o humus bibliográfico guardado nas bibliotecas. É também aquela que guia, na contemporaneidade, a formação, a construção e a atualização das coleções documentárias e dos instrumentos voltados para permitir, disseminar e valorizar o conhecimento. É bem nesses aspectos que reside a distinção entre Bibliografia e Biblioteconomia, que é a disciplina que se ocupa especificamente das técnicas e das tecnologias, portanto dos padrões, das normas e das linhas mestras e, ainda, dos softwares e dos programas que permitem às bibliotecas qualificarse como sistemas organizados e de gestão. 
Fiammetta Sabba

\section{Origens de uma consciência bibliográfica e nascimento da Bibliografia como disciplina}

A Bibliografia nasce, como é notório e como veremos, com Conrad Gesner; todavia, suas origens podem ser rastreadas a partir de um milênio antes, e é interessante seguir o amadurecimento de uma consciência bibliográfica, mesmo que de natureza ainda não disciplinar, mas sim instrumental e concreta.

Os autores anteriores a Johannes Trithemius e Conrad Gesner, acompanhando a Bibliografia em sua concretização disciplinar através de um inicial De viris illustribus liber que, aos poucos, ampliou-se e enriqueceu-se em uma perspectiva de "colaboração natural" (de mais de 130 entradas até acerca de 300), são: São Jerônimo (Séc. IV), Genádio de Marselha (Séc. V), Isidoro de Sevilha (Séc. VI), Sigeberto de Gembloux (Séc. XI), Honório de Autun (Séc. XII) e Henrique de Gent (Séc. XIII).

Esses autores realizam aquela tipologia literária denominada "Prosopografia", com a qual entende-se uma composição de repertório cujo objetivo ainda não é realizar um instrumento de recuperação eficiente e eficaz, como pode sê-lo um promptuarium, mas sim de compor uma história da literatura através da exposição sintética dos autores e de suas obras. Para tanto, a ordem interna das entradas dos autores é cronológica, baseado em seu aparecimento operacional-literário na história. O próprio “índice”, quando há um, limita-se a elencar aqueles nomes na mesma ordem em que se encontram no texto principal do liber. Essa mentalidade prosopográfica será bem próxima àquela que, muitos séculos depois, determinará a afirmação de uma tendência historico-literaria com o pressuposto de reconstruir e demonstrar o desenvolvimento e o desenrolar da produção escrita (nessa fase a referência da palavra literaria é à escrita e não a uma seção exata de produção como hoje entendemos). Essa orientação, por sua vez, deixará o legado, de um lado, à História da literatura que, de fato, concentra-se nos textos que hoje consideramos base de nossa cultura escrita em prosa e poesia e, do outro, ao cultivo de uma bibliografia nacional como representante histórico-político-geográfico da produção de escritos e de sua publicação em um “âmbito cultural confinado".

Seguem alguns exemplos extraídos de uma edição de incunábulo do Liber de viris illustribus de São Gerônimo (FIG. 1). Aqui, uma página com inúmeras entradas de autores, marcadas por uma inicial uncial evidenciada, com biografias resumidas e a citação das obras escritas por cada autor:

InCID: R. Ci. Inf. e Doc., Ribeirão Preto, v. 7, n. esp., p. 65-98, ago. 2016. 
Natureza e origem da Bibliografia: uma perspectiva disciplinar para contemporaneidade

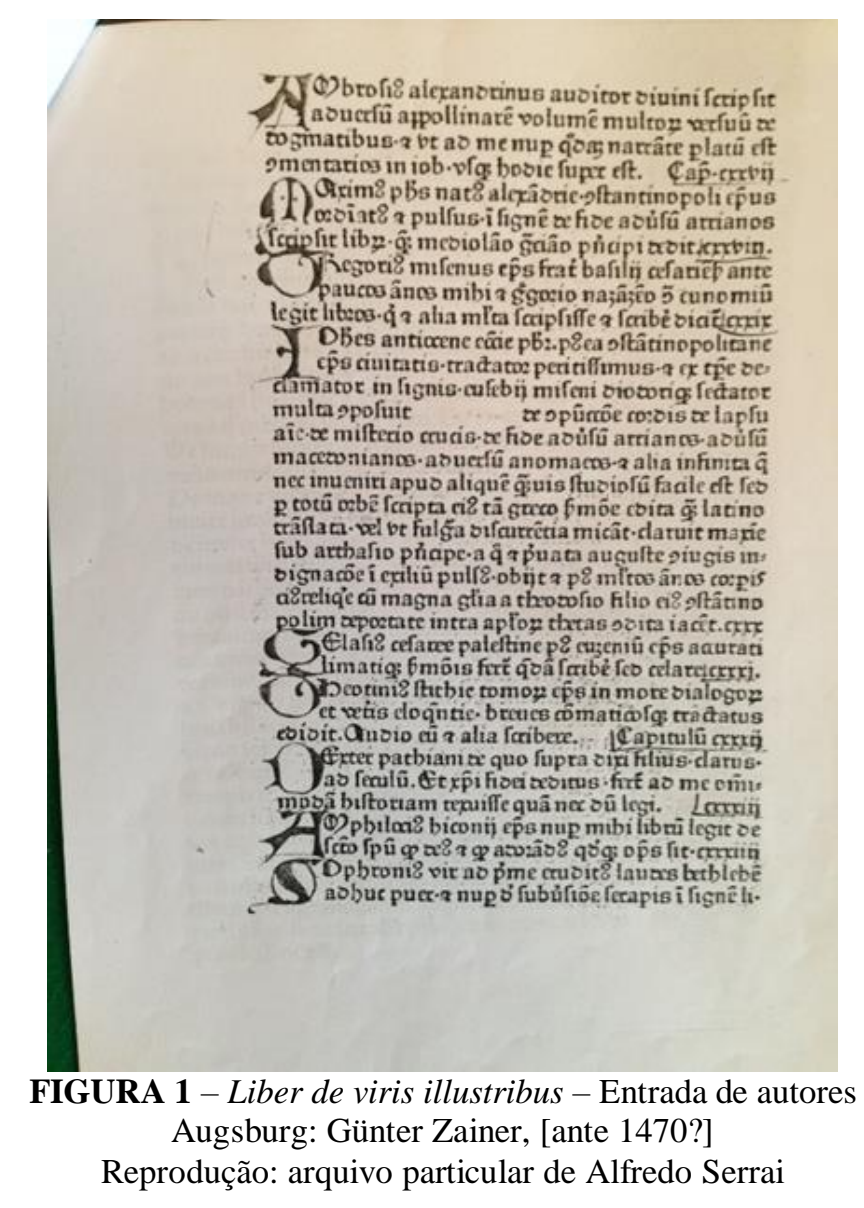

A figura a seguir (FIG. 2) mostra, por outro lado, o índice dos autores na ordem de seu aparecimento no texto; trata-se, mas do que um índice, de um 'sumário' que, aqui, é metaforicamente chamado oculus, para indicar, pelo termo 'olho', a ação de captura visual rápida das entradas evidenciadas. 


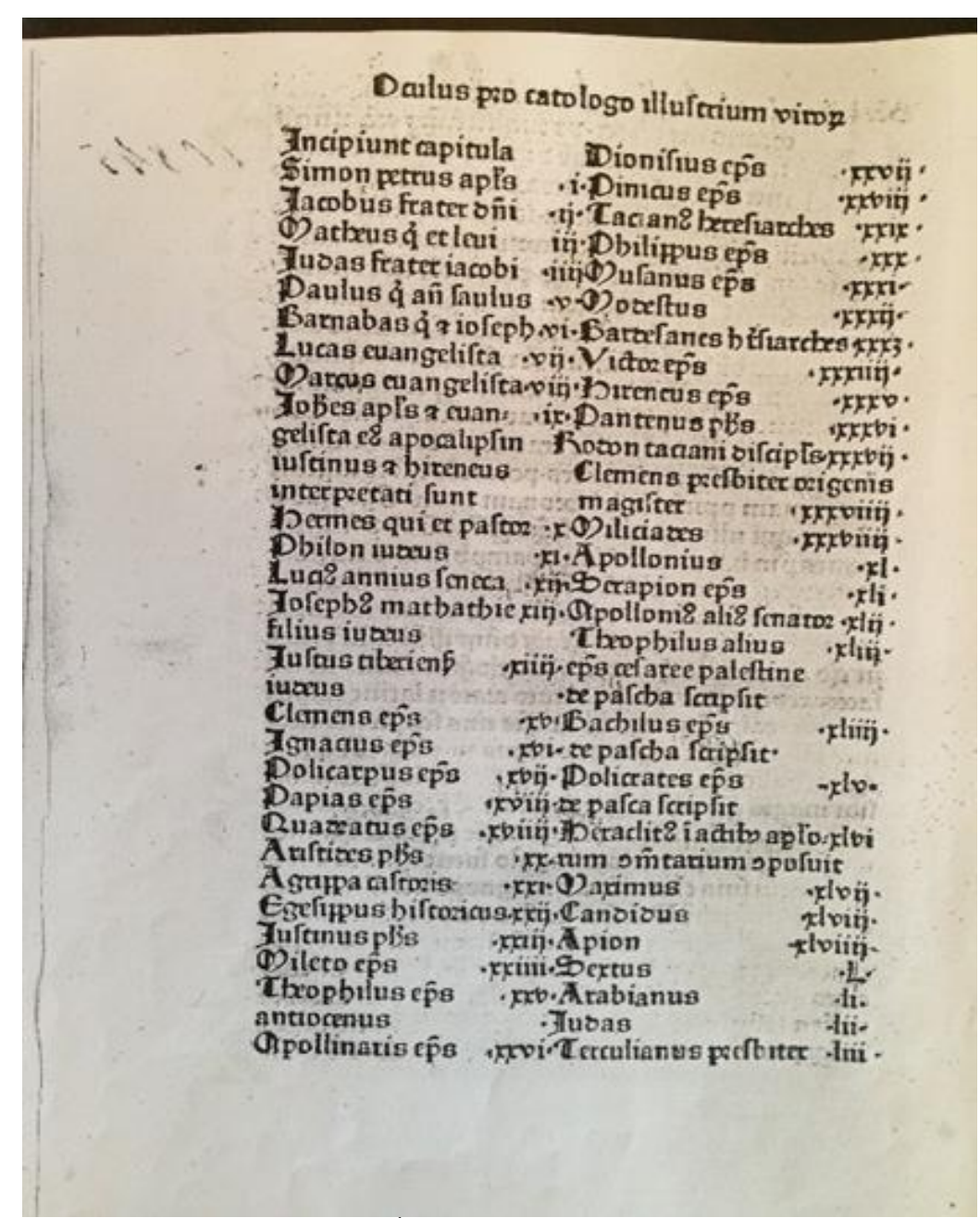

FIGURA 2 - Liber de viris illustribus - Índice dos autores na ordem de seu aparecimento no texto Augsburg: Günter Zainer, [ante 1470?]

Reprodução: arquivo particular de Alfredo Serrai

Deve ser assinalada, para completar, a aparição nesse liber de São Jerônimo da primeira "autobibliografia" (FIG. 3), à qual o autor dedica amplo espaço! 


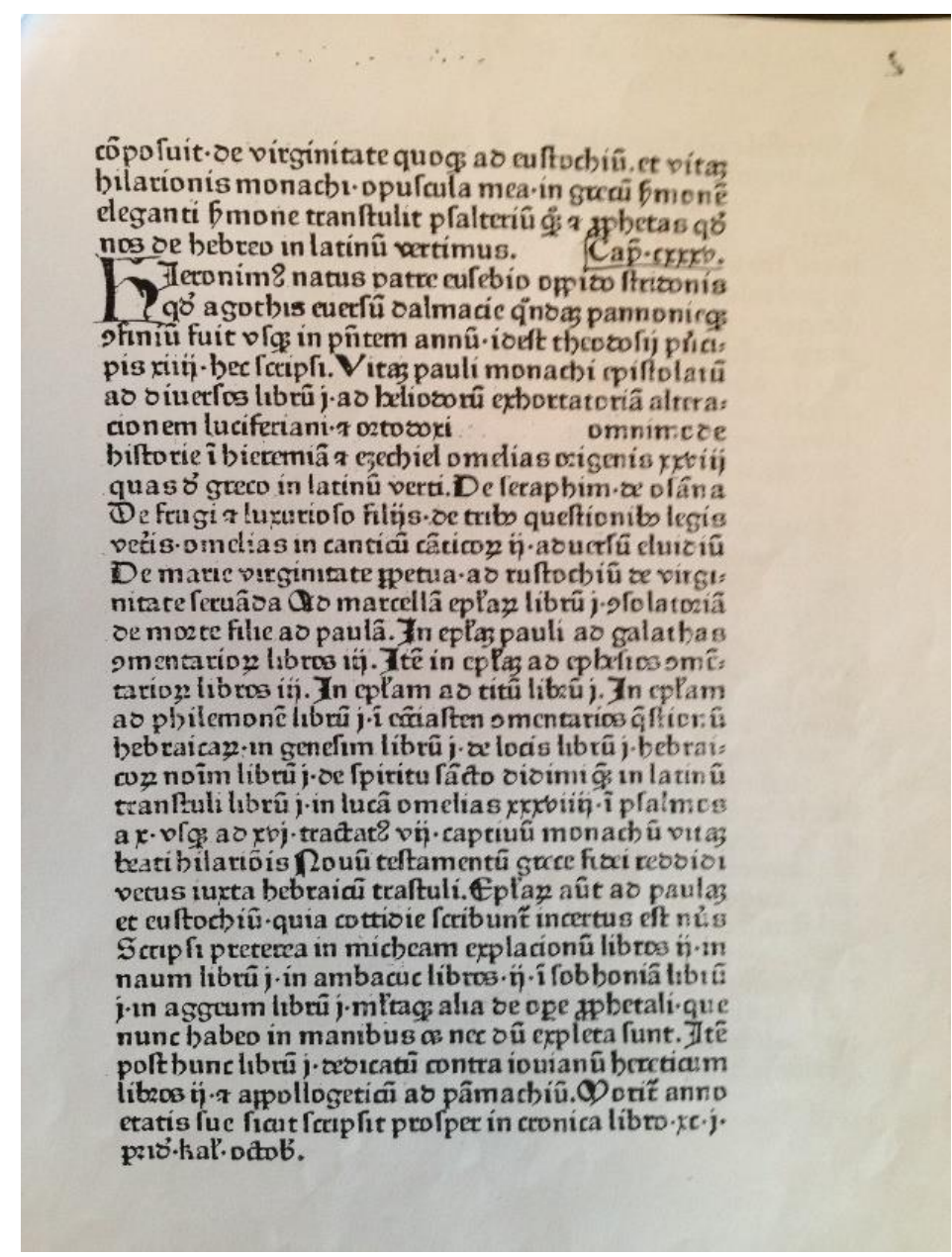

FIGURA 3 - Liber de viris illustribus - Autobibliografia Augsburg: Günter Zainer, [ante 1470?] Reprodução: arquivo particular de Alfredo Serrai

Citamos os índices de nomes, mas não menos importante e certamente mais complexa é, por outro lado, a questão da indexacão semântica. Junto aos Indices scriptorum existiam os Indices verborum et rerum, mas ainda não se tratava do índice por 'assunto' como conceito, quanto de um índice por palavras notáveis e relevantes presentes nos textos.

A função de evidência conceitual, todavia, se expressava pelos loci; em particular, havia a prática de compor loci teológicos, mas será somente Gesner que fornece à entidade bibliográfica dos loci uma arquitetura semântica universal, pura e estruturada. E veremos que Gesner antecipará soluções que, hoje, são difíceis para nós construirmos, principalmente por causa da rigidez de natureza linguística, ao mesmo tempo em que aspiramos, cada vez mais, a uma visão internacional, integradora, de troca e colaboração.

A "milenar cadeia bibliográfica", como é chamado o arco desses autores prosopográficcos, se encerra com o beneditino alemão Johannes Trithemius (Johannes Zeller, dito Trithemius pelo lugar de nascimento: Trittenheim, nascido em 1462, falecido em 
Würzburg em 1516), personagem religioso lembrado, além dos trabalhos históricos, bibliográficos e devocionais, também pelos de criptografia, como sua Steganographia.

Trithemius publicou, pela primeira vez impresso, seu importante Liber de scriptoribus ecclesiasticis (FIG. 4) em Basel, pelos tipos de Johannes Amerbach, em 1494, após algumas redações manuscritas entre 1487 e 1492. A essa seguiram mais três edições, símbolo do sucesso que a obra obteve: Paris, Berthold Rembolt, 1512 (FIG. 5); Köln, Peter Quentell, uma em 1531 e outra em 1546.

O repertório contém 963 biobibliografias expostas conforme uma estrutura tabelar, derivada da herança manuscrita (título da obra, número dos livros e incipit). Trata-se de um enorme incremento de notícias em relação ao último repertório considerado na "cadeia" acima, redigido por Enrico di Gent!

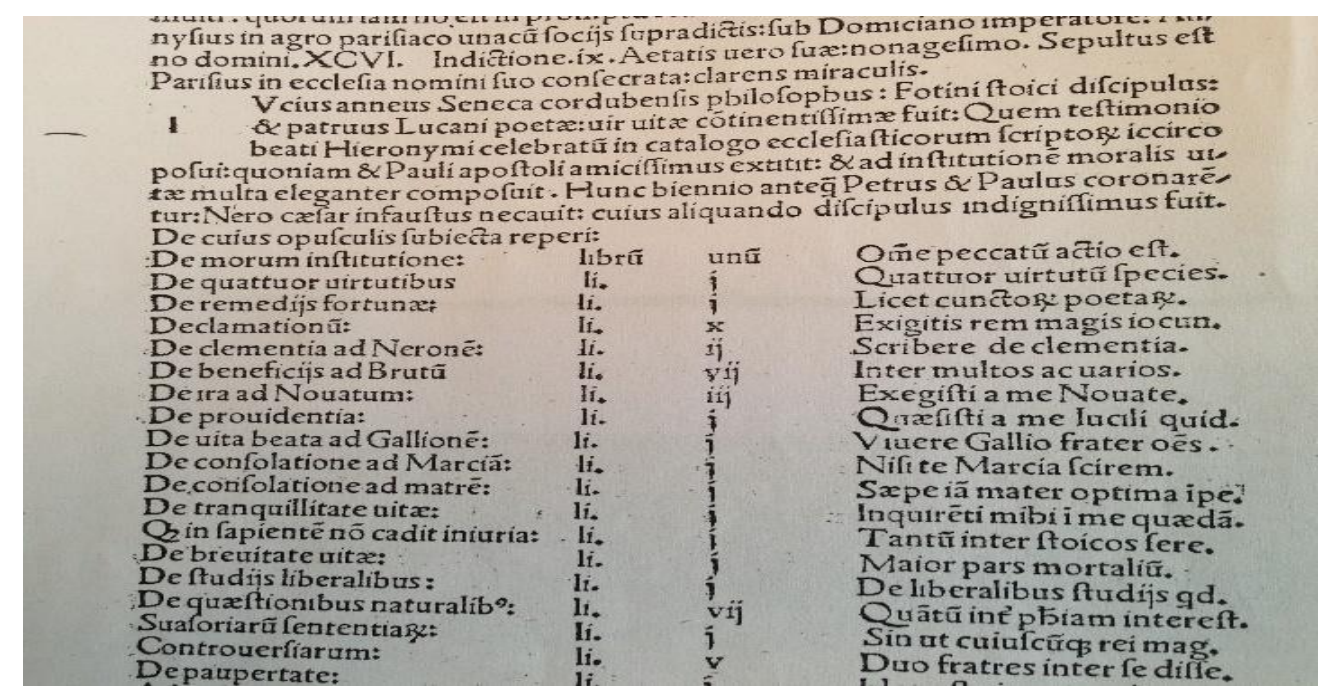

FIGURA 4 - Liber de scriptoribus ecclesiasticis - Estrutura tabelar retirada da edição de 1494 Reprodução: arquivo particular de Alfredo Serrai 


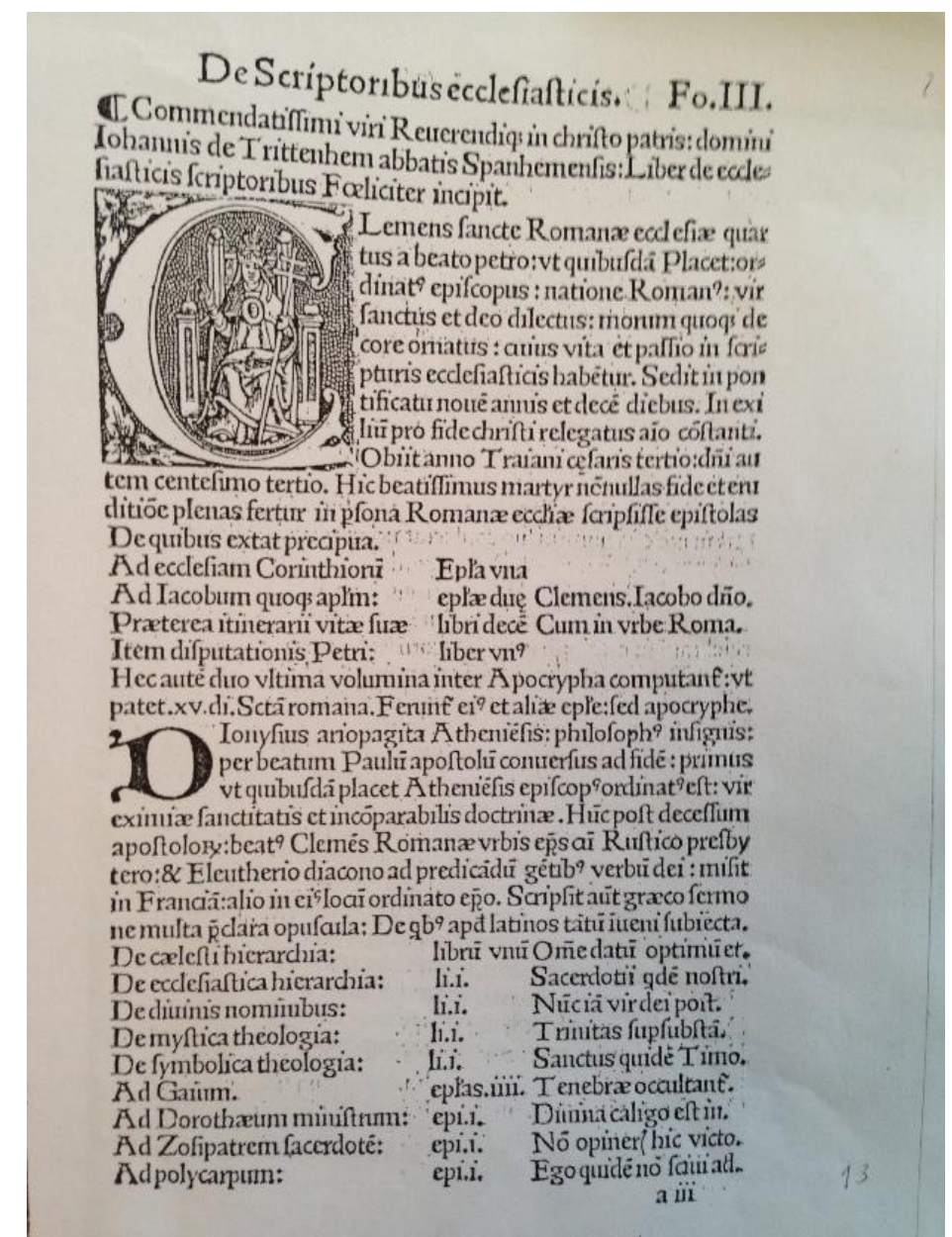

FIGURA 5 - Liber de scriptoribus ecclesiasticis - Exemplo de biobibliografia retirada da edição de 1512 Reprodução: arquivo particular de Alfredo Serrai

A novidade no índice representada pelo repertório bibliográfico trithemiano reside na proposta de um índice alfabético final dos nomes (FIG. 6) com vantagem, para a consulta, de entradas do texto principal ordenadas, sempre cronologicamente, por período de máxima fama (indicado pelo verbo "floruit"). Trithemius qualifica-se, portanto, como uma espécie de "avô da Bibliografia", pois testemunha o nascimento de uma consciência do índice também nos repertórios e nos prontuários, portanto bibliográfica. Sua lucidez, porém, não reside tanto na ordenação alfabética, quanto na ordenação do índice diferenciado a respeito daquele do texto, de maneira que o índice não é mais um resumo do conteúdo, mas um instrumento lógico de recuperação e consulta da obra. 


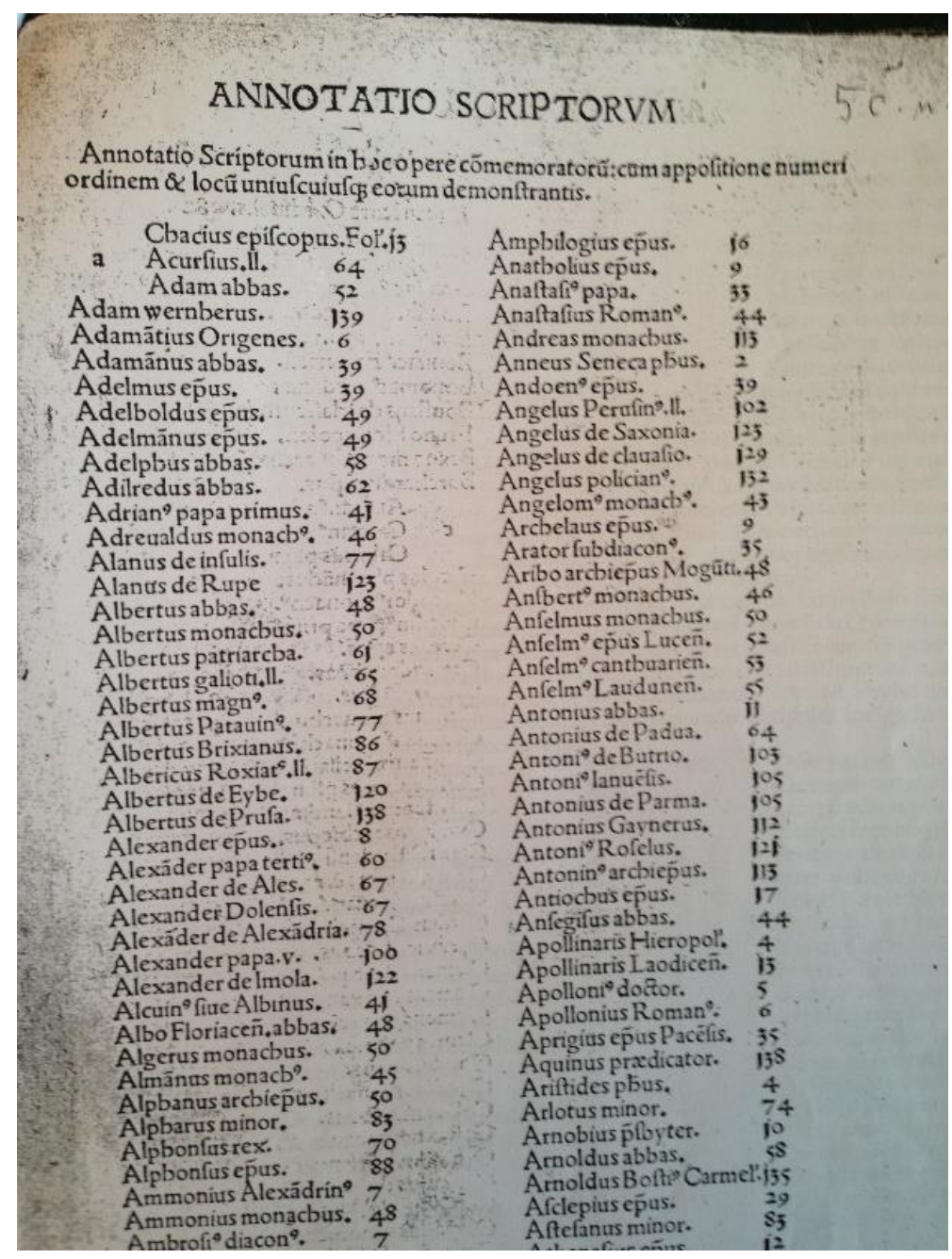

FIGURA 6 - Liber de scriptoribus ecclesiasticis - Índice final alfabético retirado da edição de 1494 Reprodução: arquivo particular de Alfredo Serrai

\section{O projeto bibliográfico de Gesner}

Se Trithemius é o antepassado da Bibliografia, o pai fundador é Conrad Gesner (Zurique, 1516-1565), cientista, erudito e bibliógrafo. Trata-se de uma personalidade ainda a ser conhecida mais aprofundadamente, apesar de ter sido cuidadosamente estudado várias vezes em perspectiva temática, desde suas obras botânicas até sua biblioteca pessoal e sua visão teológica. Nem sempre foram estudos científicos, em alguns casos Gesner foi superficialmente citado utilizando o reconhecimento que decorre de seu ecletismo de interesses como filólogo, botânico, zoólogo, médico, teólogo, bibliógrafo...

A esse perfil enciclopédico, mas ainda assim, compacto, contribuiu a proximidade com personalidades religiosas de destaque na Reforma protestante, em primeiro lugar com Ulrich Zwingli (falecido em 1531) que, em sua visão teológica - que fundou a corrente 
específica "zwingliana", distinta do luteranismo e do calvinismo - reunia e harmonizava os princípios da teologia cristã, com a herança intelectual da civilização clássica e pagã, até com o exercício da razão. Zwingli realmente foi um homem de seu tempo, um pensador renascentista, para o qual Deus correspondia à verdade e ao bem supremos, distribuindo a todos a possibilidade de acessar à verdade e de poder-se, portanto, salvar desde o momento da criação e não somente com a encarnação, como historicamente dogmatizado. A tradição pagã e a teologia cristã encontravam-se, assim, no mesmo quadro filosófico e cultural. Isso legitimou Gesner, que era seguidor, a concretizar uma obra bibliográfica que compreendia indistintamente todos que até então escreveram obras dignas de memória.

Com efeito, nos interessa exatamente a obra bibliográfica monumental de Gesner, onde se encontram comprometidos, sintetizados e representados iconograficamente todos os seus interesses, suas visões e suas experiências em uma estrutura holística, e onde cada fiapo de saber encontrou o lugar que lhe cabia no universo do conhecimento.

Gesner produziu para ser impressa a Bibliotheca Universalis (FIG. 7), editada em Zürich pelo tipógrafo Christoph Froschauer em 1545, à qual seguiram as Pandectae, publicadas em dois volumes, o primeiro em 1548 (FIG. 8) e o segundo em 1549 (FIG. 9). Os três volumes são entregues ao tipógrafo por Gesner separadamente, todavia - como já demonstrei - integram-se perfeitamente em um único projeto bibliográfico. Trata-se, de fato, de um imenso trabalho bibliográfico caracterizado pela intenção de oferecer o quadro total da realidade científico-literária da metade do século XVI.

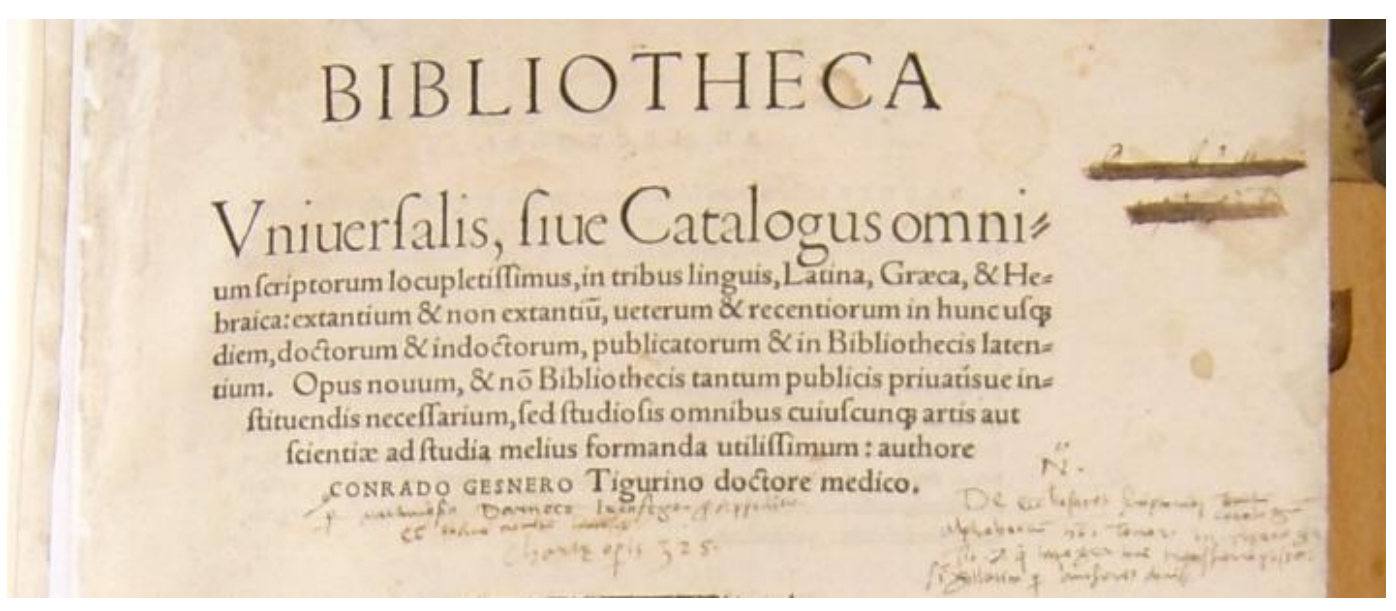

FIGURA 7 - Título do frontispício de Bibliotheca Universalis (1545) Reprodução: arquivo particular de Alfredo Serrai 


\section{PANDECTARVMSIVE}

Partitionum uniuerfalium Con

radi Gefneri Tigurini, medici

\& philofophixprofeffo ris, libri $\overline{\mathbf{x x}}$.

AD LECTORES.

SE CV N D V S hic B I B L IO T H E C A E nofirx Tomus eff,totius philofophix \& omnium bonarum artium atg fudiorum Locos communes $\&$ Ordines uniuerfales
fimul $\&$ particulares complestens. Vos lucrum hocingens ad fua quiff ftudia reportate, fimul \& particulares complectens. Vos lucrum hoc ingens ad fua quilģ fudia reportate,
\& grati effote authori propter tantum Opus feliciter diuins gratia inchoatum : non quod 2.grati effote authori propter tantum Opus feliciter diuina gratia inchoatum : : non quod
idem abfoluendum unquam ab ipfo expeetari debeat, fed ut quifg fibi pro ftudiorum fuo rum ufu id accommodet. Licebit enim ftudiofis quicquid ufquam memoratu dignum lea gendo occurre, facile huc in fuos quafi nidos recondere, unde fuo tempore nur fus deproemant. Et prodiue quidē hoc erit factu illi, qui philofophix partes aţ̧ differentias cognouerì,aut faltem Titulos, quos fingulis ximus, iterum atqy iterum inf pexcrit.

Librorum enumeratio fequente pagina continetur.

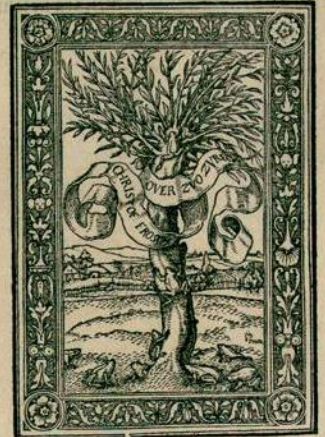

TIGVRI EXCVDEBAT CHRISTOPHORVS Frofchouerus, Anno M. D, XLV III.

FIGURA 8 - Página de rosto do I volume das Pandectae (1548)

Disponível em: <http://www.e-rara.ch/zuz/content/pageview/1160095> 


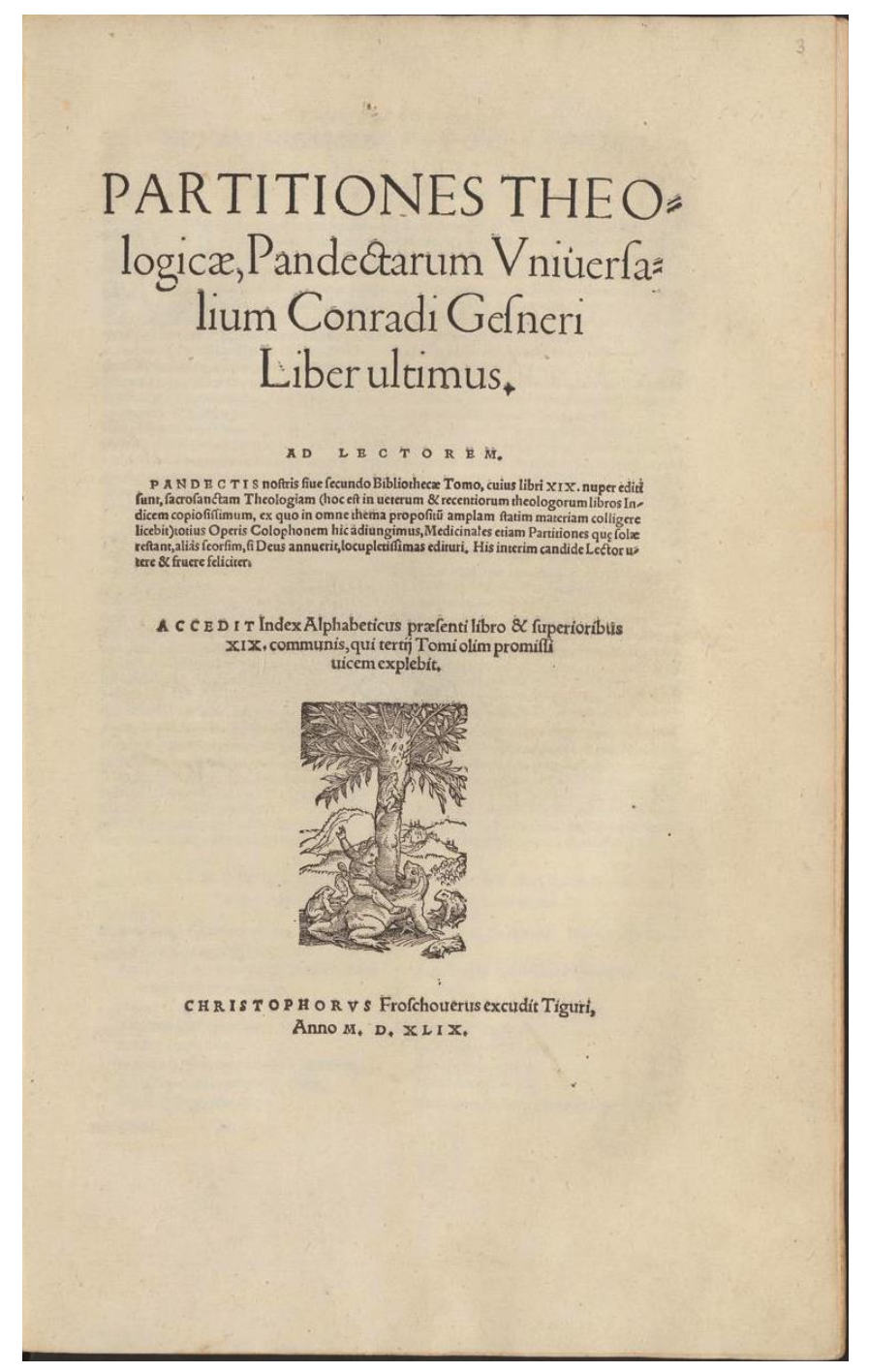

FIGURA 9 - Página de rosto do II volume das Pandectae (1549)

Disponível em: <http://www.e-rara.ch/zuz/content/pageview/678541>

A única chave para entender o real porte informacional do repertório, tanto em termos documentários quanto exegéticos, foi considerar as fontes de informação utilizadas para compô-lo e sua representatividade bibliográfica em relação à cultura escrita disponível na época. Como consequência, foi possível medir seu grau de 'universalidade' face aos propósitos desejados e aos instrumentos disponíveis. Isso não tinha sido aprofundado, de fato, antes da publicação de meu volume La Bibliotheca Universalis di Conrad Gesner: monumento della cultura europea (Roma, Bulzoni, 2012), no qual confluiu também minha tese de Doutorado em Ciências Bibliográficas, Arquivísticas e Documentárias, defendida em Udine em 2009. O trabalho, porém, foi publicado três anos mais tarde, pois minha análise do repertório continuara e se tornou portanto necessário reelaborar os resultados para pode-los divulgar de forma clara também para os leigos no campo da Bibliografia. Já ficou estabelecido o interesse por Conrad Gesner e sua fama, que estavam se ampliando 
rapidamente e "popularizando", em vista, também, das comemorações marcadas para 2016.

\section{As fontes de Bibliotheca Universalis}

As fontes das quais teria sido atingido o material encontra-se assinaladas na Epistola nuncupatoria da Bibliotheca e em algumas partes das Pandectae, bem como, frequentemente no próprio texto do repertório. Em geral, as sinalizações bibliográficas, tanto aquelas somente literárias quanto as editoriais, decorrem de:

- as autópsias realizadas pessoalmente sobre o material impresso de propriedade do próprio Gesner e de seu círculo de amizades e eruditos, especificamente médicos e filólogos, ou guardado em bibliotecas às quais teve acesso durante suas inúmeras viagens;

- a correspondência com os amigos e as conversas com os doutos;

- os catálogos dos tipógrafos e dos livreiros recuperados nas feiras comerciais ou que lhes foram enviados;

- os índices das bibliotecas públicas e particulares, tanto verificados pessoalmente como obtidos em cópia;

- os repertórios bibliográficos que antecederam o dele, entendendo com isso tanto obras de conteúdo bibliográfico, como repertórios bibliográficos propriamente ditos; Gesner usou, de fato, uma ampla variedade de repertórios, desde os dos prosopógrafos que o antecederam - portanto desde São Jerônimo até o abade Johannes Trithemius - até os de especialistas no Direito, Poesia, Medicina e Botânica (Lilio Gregório Giraldi, Pietro Crinito, Symphorien Champier, Otho Brunfels, Leonhard Fuchs, Raffele Maffei dito Volaterranus, Johann Fichard, Bernardino Rutilio, Giovanni Nevizzano...).

A parte mais notável dos "recipientes informativos" dos quais Gesner obteve notícias, porém, decorre inegavelmente de suas viagens, em primeiro lugar daquele para a Itália em 1543. Gesner viajou, naquela época, para Ferrara, Verona, Como, Bolonha e Veneza, nessa última a convite do embaixador espanhol Diego Hurtado de Mendoza.

A colaboração entre estudiosos e eruditos era a base da comunidade literária, a troca de textos e notícias era um bem coletivo. Haviam ocasiões anuais de encontro, como a permanência nas termas ou as feiras das Nundinas, das quais nasciam colaborações, amizades, convites recíprocos, e tudo isso facilitava, ao lado da circulação dos eruditos, também e acima 
de tudo aquela das notícias de textos e livros, além dos próprios livros, bem como de cópias dos catálogos. As cidades italianas, tornando-se instituições-hospedeiras do patrimônio de livros gregos depois da fuga dos gregos de Corfù, haviam se tornado uma meta almejada e privilegiada. Em particular, para estudar, eram visitadas, frequentadas e escolhidas pela presença dessa literatura as cidades de Veneza e Pádua.

\section{A importância e o papel dos repertórios bibliográficos na tradição cultural}

A tradição anterior precisava ser conhecida, boa parte precisava ser ainda descoberta, para depois ser utilizada como base para novas pesquisas e empreitadas de estudo e divulgação. Ainda não estavam firmes os conceitos de plágio, direito autoral, paternidade autoral subtraída, mas os eruditos eram, em geral, movidos no âmbito de uma ecumenicidade extraordinária. Não se tratava de descobrir estradas desconhecidas, mas sim de seguir, aperfeiçoando, aprofundando e documentando o que a civilização humana traçara ao longo do caminho, com a finalidade de prestar, sempre, contas explícitas e públicas.

Porém, além de conotar o patrimônio científico e literário, os repertórios acabavam fotografando e fixando o status de coleções e bibliotecas individualizadas, bem como de épocas e de suas tendências e preferências culturais. São incluídos ambientes religiosos e laicos, bibliotecas públicas e particulares, essas últimas, com frequência, pela liberalidade de acesso e consulta eram mais públicas das que eram pela gestão e definição estatutária. Paradoxalmente, é por esse motivo que as coleções particulares, as mais ricas e mais próximas da perfeição de um ponto de vista bibliográfico, eram as mais cobiçadas pelos eruditos.

Da análise de uma qualquer coleção particular entre as muitas citadas na Bibliotheca emerge como, graças ao repertório gesneriano, é possível reconstruir, ainda que, às vezes, parcialmente, a coleção de livros de um erudito, tanto em sua composição quanto em sua qualidade literária e bibliográfica, portanto com o repertório gesneriano se confirma, dessa maneira, bem na função de testemunha, muitas vezes única, relativa a coleções de livros particulares interessantes na perspectiva da reconstrução do ambiente erudito do século XVI.

Gesner, mesmo quando no prefácio à Bibliotheca fala da necessidade de registrar o patrimônio para lhe garantir pelo menos notícia no futuro, não pensava em realizar uma testemunha escrita de bibliotecas individuais ou coleções. Isso, todavia, aconteceu de maneira involuntária face a primeira intenção. Com efeito, ele não se concentrara tanto nos exemplares

InCID: R. Ci. Inf. e Doc., Ribeirão Preto, v. 7, n. esp., p. 65-98, ago. 2016. 
e em suas características, nem nas edições, mas sim - e este é o fato bibliográfico principal nas obras e nos textos. Gesner não realizou um repertório "universal" completo de todas as edições manuscritas e impressas alcançadas, mas de todas as obras de que recebera notícia tanto direta quanto indireta, mesmo quando se tratava de obras perdidas. Além disso quando, como filólogo experiente, ele sinalizava a presença de mais exemplares para colacionar, o fazia com a finalidade de oferecer aquela documentação que podia servir para produzir novas edições impressas mais corretas que as anteriores. $O$ foco era, portanto, a melhoria da produção intelectual, literária e científica.

Assim, constituem o tecido base da Bibliotheca as fontes catalográficas, as de tipo literário-bibliográfico inerentes, em particular ao Direito, à Medicina, à Poesia, e as bibliografias propriamente ditas, isso é, na terminologia gesneriana, os Catalogi scriptorum.

Reservatório informacional riquíssimo foram alguns catálogos de bibliotecas principalmente italianas: em Veneza a de Bessarião, a de Hurtado de Mendoza, de Santo Antonio do Castelo, do Mosteiro de São João e Paulo; em Bolonha a Biblioteca de São Salvador; em Roma a Vaticana, e em Florença a Medíceo-Laurenciana. Se registra também uma presença notável de coleções estrangeiras, como aquelas particulares de Desiderius Erasmus, de Conrad Peutinger, de Cristoph Clauser, de Alexander Brassicanus, além daquela pública de Augsburg.

Entre as fontes protagonistas da Bibliotheca lembramos também dos catálogos de venda de tipógrafos e editores. Particularmente ricas são as notícias bibliográficas provenientes das áreas alemã e francesa, às quais Gesner era mais ligado, seguidas pela área italiana, cuja presença é justificada pelo fato de aí se preservar a maioria das obras ainda inéditas em latim e, principalmente, em grego.

Em meu volume qualifiquei os catálogos de editores, tipógrafos e livreiros como "fonte oculta", na medida em que não abertamente declarada por Gesner nas declaratórias da Bibliotheca. A essa tipologia de fontes pertencem os catálogos de venda de alguns editores publicados em introdução para 7 dos 20 livros dos quais se compõem as Pandectae gesnerianae, e são os de Froschauer, Gymnich, Wechel, Gryphe, Frellon, Manuzio e Froben.

Percebe-se plenamente, por essa apresentação exegética como Gesner trabalhara sem parar em busca de notícias sobre material literário e bibliográfico, utilizando os mais variados canais. Isso foi possível apesar das dificuldades de comunicação e de deslocamento, pois era 
suportado por uma tradição anterior bem consolidada e por uma sociedade culta e erudita, consciente do valor daquilo que conhecia, manuseava, possuía e estudava e que, portanto, era colaborativa, generosa, impregnada de valores intelectuais altos e nobres. A colaboração entre os estudiosos era à base da realização das empreitadas bibliográficas da amplo fôlego; cada um colocava a disposição os textos e as notícias que possuía, havia verdadeiras trocas e tudo que decorria disso era concebido em primeiro lugar como bem comum, e somente de forma indireta como mérito pessoal.

Os repertórios bibliográficos desempenhavam, como já dito, obrigatoriamente, não somente as funções de simples registro do patrimônio escrito, mas também as de atestação e evidência do que ainda não tinha sido impresso, principalmente de tornar público o mesmo para que sua existência fosse conhecida e sua edição impressa fosse promovida. Além de fixar os elementos do patrimônio científico e literário, os repertórios acabavam, indiretamente, por fotografar o status de instituições livreiras individuais, ou de coleções e, por consequência, o humus cultural das cidades em que elas se encontravam. Muitas dessas coleções, como já assinalamos, mesmo não sendo ainda propriamente "da cidade", mas privadas como origem e como manutenção, eram "públicas", lá onde o conceito de público não se referia à propriedade mas ao livre e consentido acesso para os estudiosos.

\section{A indagação semântica gesneriana nas Pandectae}

Vamos agora observar as Pandectae, que representam a segunda parte do projeto bibliográfico gesneriano e, de fato, a seção mais complexa. Para compreendê-las somos obrigados a uma referência contínua à primeira parte, onde as informações foram registradas por Gesner de maneira extensa e não sintética como nessa segunda. Elas se revelam em toda sua utilidade e preciosidade informacional somente se o conteúdo, a arquitetura e a concreta contribuição bibliográfica da primeira parte forem bem conhecidas. A dificuldade de interpretação das Pandectae impediu sua disseminação comercial editorial e, por isso, o estudo e a pesquisa; mas agora que se disseminaram as cópias digitais para acesso público online de sua edição (1548 e 1549), se observa uma explosão de seu uso com a finalidade de reconstituir a história bibliográfica das disciplinas individuais: em particular, até agora, da música, da medicina e das artes aplicadas.

As Pandectae se compõem de 21 livros, os primeiros 19 publicados no I volume de 
1548, o livro XXI no II volume de 1549, ficando de fora o livro XX, dedicado à Medicina, que não veio à luz a tempo, como se Gesner tivesse dedicado um cuidado particular ao que espelhava sua formação profissional principal. Da preparação do livro XX temos porém testemunha, através do material bibliográfico médico coletado por Hieronymus Wolph, do qual hoje se encontram na Zentralbibliothek de Zurique três volumes manuscritos, por ele organizados em 1596, enquanto uma parte do material chegou à Noruega por heranças e vendas. O projeto das Pandectae, levado quase completamente a cabo é composto pelos Libri:

I. De grammatica et philologia

II. De dialectica

III. De rhetorica

IV. De poetica

V. De arithmetica

VI. De geometria

VII. De musica

VIII. De astronomia

IX. De astrologia

X. De divinatione cum licita tum illicita et magia

XI. De geographia

XII. De historiis

XIII. De diversis artibus illiteratis, mechanicis et aliis humanae vitae utilibus

XIV. De naturali philosophia

$\mathrm{XV}$. De prima philosophia seu metaphysica et theologia gentilium

XVI. De morali philosophia

XVII. De oeconomica philosophia

XVIII. De re politica, id est civili et militari

XIX. De iurisprudentia indices tres

XX. De re medica

XXI. De theologia christiana

É também interessante analisar a grade das classes que Gesner insere no último volume e último livro dedicado à Teologia (FIG. 10), na qual expõe sua visão cultural pessoal, que provavelmente reflete aquela de seu ambiente, e nos revela melhor as dificuldades histórico-reconstitutivas que ilustramos anteriormente na parte dedicada à relação entre Bibliografia e História das bibliotecas. Na Filosofia, que embasa todas as artes e as 
ciências, se enxertam disciplinas 'preparatórias' e disciplinas 'substanciais'. As preparatórias se especificam em 'necessárias', como as matemáticas - aritmética, geometria, música, astronomia e astrologia - e em 'sermocinais' ou seja, para exposição - gramática, retórica, poesia, e dialética -, ou 'ornamentais' no sentido de úteis para aperfeiçoar todos os outros estudos, com geografia, história, magia e outras artes. As 'substanciais', por outro lado, se constituem em física, metafísica, teologia cristã e ética, na qual se encontram economia e política que, por sua vez, compreende o direito.

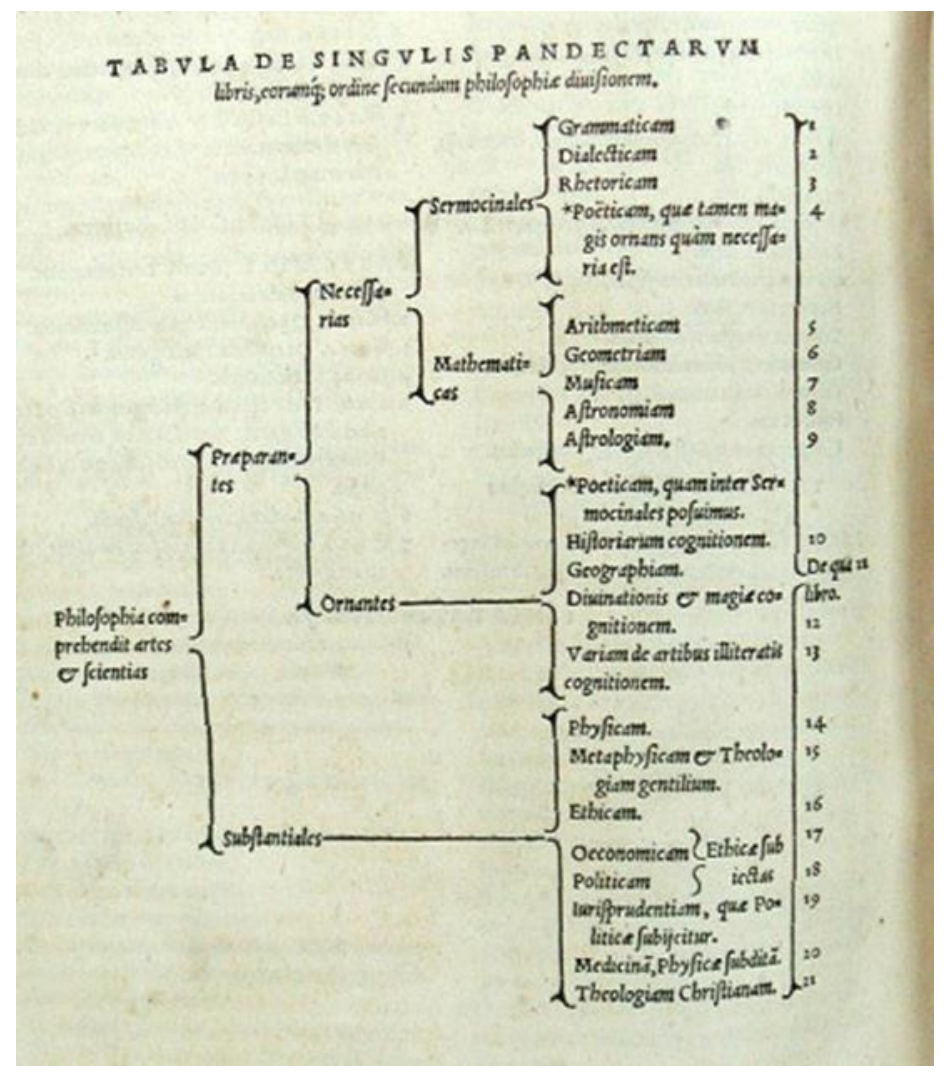

FIGURA 10 - Tabula das classes, retirada do volume II das Pandectae (1549) Disponível em: < http://www.e-rara.ch/zuz/content/pageview/625744>

Os 21 (ou 20) livros contêm o material bibliográfico já presente na Bibliotheca Universalis sob o nome dos autores, aqui porém exposto através da granulação de seu conteúdo a partir da disciplina de referência até chegar ao núcleo semântico chamado locus communis o particularis, correspondente, grosso modo, ao nosso atual assunto catalográfico. Em relação ao volume de 1545, estão compreendidas as obras poligráficas (ex. de autores gregos e latinos com listas de loci communes), as obras anteriormente não conhecidas, aquelas anônimas que no volume de 1545 não podiam ser apresentadas sob algum autor, aquelas, obviamente, publicadas depois de 1545 ou anteriormente não conhecidas por Gesner, mas também os scolia, os parágrafos, os índices, as traduções e os compêndios que na estrutura alfabética não encontravam "autonomia" autoral suficiente.

InCID: R. Ci. Inf. e Doc., Ribeirão Preto, v. 7, n. esp., p. 65-98, ago. 2016. 
A arquitetura semântica encontrava, assim, ulteriores subdivisões dentro dos livros, até alcançar o núcleo semântico específico:

Livros / Partições

Títulos

Partes

Parágrafos

Loci communes

Loci particulares

As Pandectae contribuem bastante à história das classificações: a matriz semântica reúne, através do assunto todas as presenças e os derivados textuais da obra (traduções, comentários, epítomes, prefácios...) reconstituindo assim a configuração completa de participações e contribuições que formam a progênie colateral e seguinte das obras e das edições.

Ainda sublinhamos o fato de a classificação aplicada por Gesner aos Libri Pandectarum ser por conceitos; dessa maneira, a mesma coisa é classificada de forma diferente conforme a disciplina em que se encontra; por outro lado, na III parte da Bibliotheca Universalis, inédita, que dizia a respeito de um índice alfabético por assunto, muitas acepções teriam desaparecido como entidades e como conceitos. Trata-se de um ponto crucial para as classificações: enquanto nos 21 livros gesnerianos os conceitos ocupavam o lugar que lhes cabia na arquitetura sistemática, a elaboração moderna de assuntos às vezes resulta ainda inadequada, ainda excessivamente ancorada à impostação de natureza terminológica e linguística mais do que à semântica e, para sanear esses pontos críticos, foram individualizadas nos tesauros e listas de assuntos catalográficos "facetas" para qualificar e definir as relações semânticas entre os termos (mas, de fato, não entre os conceitos!). Em tempos de trocas internacionais contínuas e de abertura imediata e global dos produtos científicos é inaceitável a submissão, ainda, a esses vínculos linguísticos, mas é necessário admitir que Gesner teve a sorte de poder recorrer ao latim que, representando uma espécie de 'língua franca' facilitava as operações, tornando-as comuns.

Para exemplificar as questões aqui expostas segue um exemplo retirado do Nuovo Soggettario italiano realizado pela Biblioteca Nacional Central de Florença (FIG. 11). 
Natureza e origem da Bibliografia: uma perspectiva disciplinar para contemporaneidade

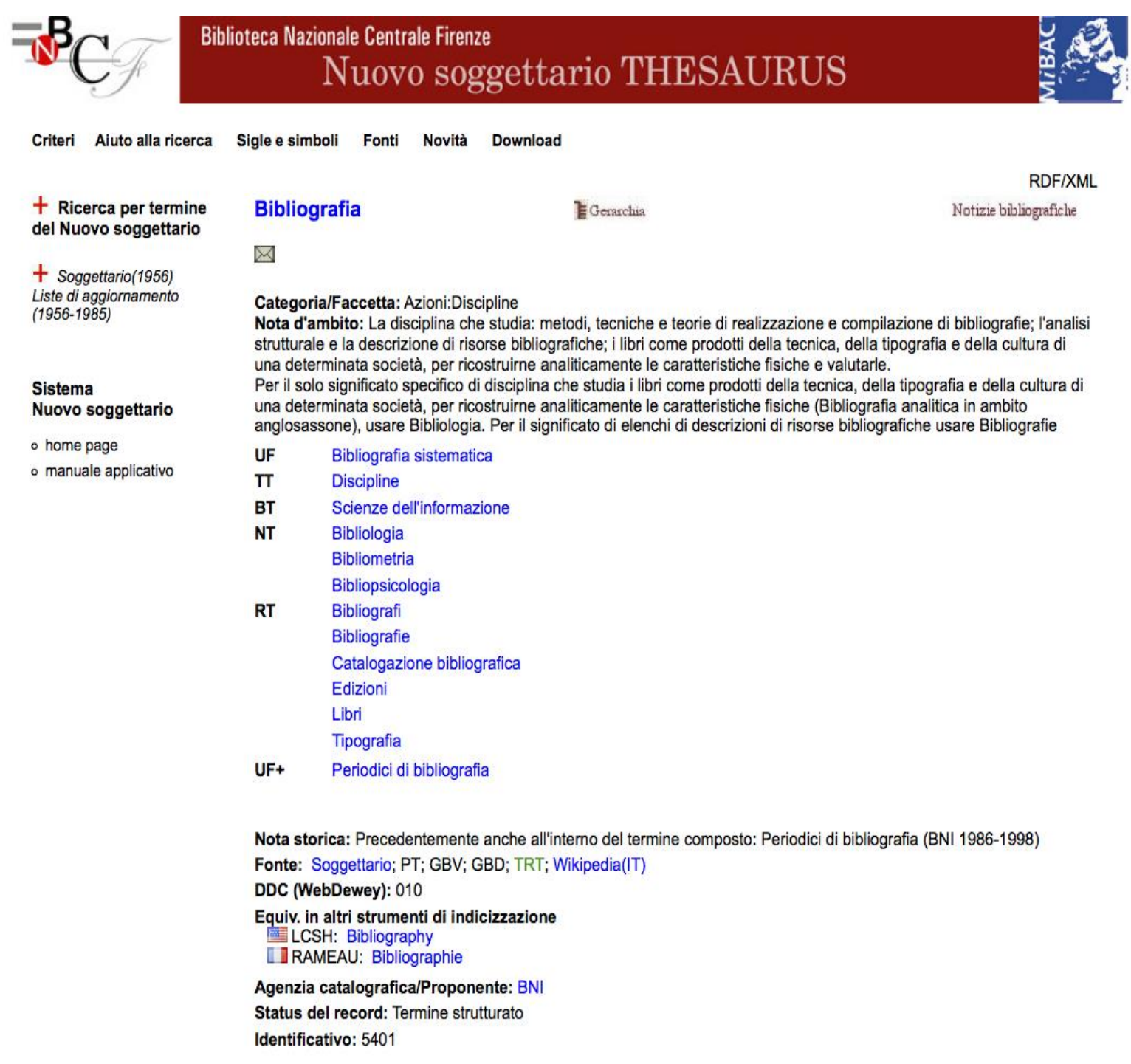

FIGURA 11 - Pesquisa realizada para 'Bibliografia' no Thesaurus do Nuovo Soggettario italiano (Florença, BNCF, 2007) ${ }^{2}$

Disponível em: <http://thes.bncf.firenze.sbn.it/termine.php?id=5401\&menuR=2\&menuS=2>

\begin{abstract}
2 Tradução:
Categoria/Faceta: Ações:Disciplinas.

Nota de âmbito: A disciplina que estuda: métodos, técnicas e teorias de realização e compilação de bibliografias; a análise estrutural e a descrição de recursos bibliográficos; os livros como produtos da técnica, da tipografia e da cultura de uma determinada sociedade, para reconstituir analiticamente suas características físicas e avaliá-las. Só pelo significado específico de disciplina que estuda os livros como produtos da técnica, da tipografia e da cultura de uma determinada sociedade, para reconstituir analiticamente suas características físicas (Bibliografia analítica em âmbito anglo-saxônico), usar Bibliologia. Para o significado de listas de descrições de recursos bibliográficos usar Bibliografias.
\end{abstract}

Nota histórica: Anteriormente também no interior do termo composto: Periódicos de bibliografia (BNI 19861998).

InCID: R. Ci. Inf. e Doc., Ribeirão Preto, v. 7, n. esp., p. 65-98, ago. 2016. 


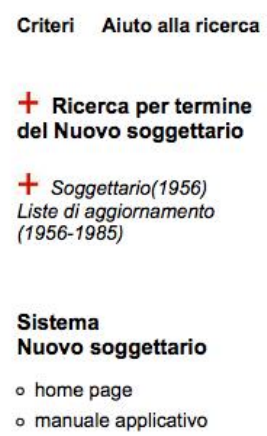

Sigle e simboli Fonti Novità Download

gerarchia del termine

+ Ricerca per termine
del Nuovo soggettario

+ Soggettario(1956)

Liste di aggiornamento

Sistema

- home pag

- manuale applicativo

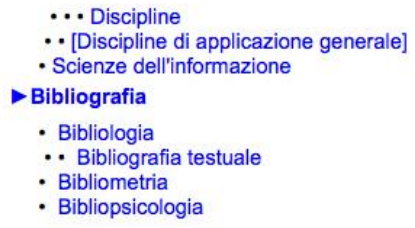

FIGURA 12 - Hierarquia do termo Bibliografia

Disponível em: <http://thes.bncf.firenze.sbn.it/gerarchia.php?id=5401\&menuR=2\&menuS=2>

QUADRO 1 - Siglas das relações semânticas utilizadas no Thesaurus do Nuovo Soggettario

\begin{tabular}{|c|c|c|c|}
\hline Sigla & Sigla livre & $\begin{array}{l}\text { Tipologia de } \\
\text { relação }\end{array}$ & Significado \\
\hline BT & $\begin{array}{l}\text { Broader term } \\
\text { (Termo genérico) }\end{array}$ & Relação hierárquica & $\begin{array}{l}\text { Relação entre um termo preferido } \\
\text { e o termo preferido } \\
\text { imediatamente acima (mais } \\
\text { geral). A relação recíproca é NT }\end{array}$ \\
\hline HSEE & $\begin{array}{l}\text { Historical see } \\
\text { (Variante histórica de) }\end{array}$ & $\begin{array}{l}\text { Relação de variante } \\
\text { histórica (relação } \\
\text { não standard) }\end{array}$ & $\begin{array}{l}\text { Relação entre um termo não mais } \\
\text { preferido (variante histórica) e o } \\
\text { novo termo preferido que o } \\
\text { substitui. A relação recíproca é } \\
\text { HSF }\end{array}$ \\
\hline HSF & $\begin{array}{l}\text { Historical seen for } \\
\text { (Há como variante histórica) }\end{array}$ & $\begin{array}{l}\text { Relação de variante } \\
\text { histórica (relação } \\
\text { não standard) }\end{array}$ & $\begin{array}{l}\text { Relação entre um termo preferido } \\
\text { e uma sua variante histórica. A } \\
\text { relação recíproca é HSEE }\end{array}$ \\
\hline NT & $\begin{array}{l}\text { Narrower term } \\
\text { (Termo específico) }\end{array}$ & Relação hierárquica & $\begin{array}{l}\text { Relação entre um termo preferido } \\
\text { e o termo preferido } \\
\text { imediatamente subordinado (mais } \\
\text { específico). A relação recíproca é } \\
\text { BT }\end{array}$ \\
\hline RT & $\begin{array}{l}\text { Related term } \\
\text { (Termo associado) }\end{array}$ & Relação associativa & $\begin{array}{l}\text { Relação recíproca entre dois } \\
\text { termos correlatos }\end{array}$ \\
\hline
\end{tabular}

InCID: R. Ci. Inf. e Doc., Ribeirão Preto, v. 7, n. esp., p. 65-98, ago. 2016. 
Natureza e origem da Bibliografia: uma perspectiva disciplinar para contemporaneidade

\begin{tabular}{|c|c|c|c|}
\hline SNR & $\begin{array}{l}\text { Scope Note Reference } \\
\text { (Nota de escopo) }\end{array}$ & $\begin{array}{l}\text { Relação de citação } \\
\text { na nota de escopo } \\
\text { (relação não } \\
\text { standard) }\end{array}$ & $\begin{array}{l}\text { Relação entre um termo não } \\
\text { preferido citado na nota de } \\
\text { escopo de um termo preferido e o } \\
\text { próprio termo preferido. A } \\
\text { relação recíproca é SNX }\end{array}$ \\
\hline SNX & $\begin{array}{l}\text { Is referenced in Scope Note } \\
\text { (É referenciado na nota de escopo) }\end{array}$ & $\begin{array}{l}\text { Relação de citação } \\
\text { na nota de escopo } \\
\text { (relação não } \\
\text { standard) }\end{array}$ & $\begin{array}{l}\text { Relação entre um termo preferido } \\
\text { e um termo não preferido citado } \\
\text { em sua nota de escopo. A relação } \\
\text { recíproca é SNR }\end{array}$ \\
\hline TT & $\begin{array}{l}\text { Top Term } \\
\text { (Termo tópico) }\end{array}$ & $\begin{array}{l}\text { Relação hierárquica } \\
\text { com o termo tópico }\end{array}$ & $\begin{array}{l}\text { Relação entre um termo } \\
\text { preferido e o termo tópico de sua } \\
\text { hierarquia }\end{array}$ \\
\hline UF & $\begin{array}{l}\text { Used for } \\
\text { (Usado para) }\end{array}$ & $\begin{array}{l}\text { Relação de } \\
\text { equivalência }\end{array}$ & $\begin{array}{l}\text { Relação entre um termo preferido } \\
\text { e um seu sinônimo ou quase- } \\
\text { sinônimo não preferido (used } \\
\text { for). A relação recíproca é USE }\end{array}$ \\
\hline $\mathrm{UF}+$ & $\begin{array}{l}\text { Used for }+ \\
\text { (Está no termo composto não favorito) }\end{array}$ & $\begin{array}{l}\text { Relação de } \\
\text { decomposição }\end{array}$ & $\begin{array}{l}\text { Relação entre os termos } \\
\text { preferidos derivados pela } \\
\text { decomposição de um termo } \\
\text { composto não mais aceito e } \\
\text { próprio composto. A relação } \\
\text { recíproca é USE+ }\end{array}$ \\
\hline USE & Use (Usar) & $\begin{array}{l}\text { Relação de } \\
\text { equivalência }\end{array}$ & $\begin{array}{l}\text { Relação entre um termo não } \\
\text { preferido e o termo preferirod } \\
\text { (use). A relação recíproca é UF }\end{array}$ \\
\hline USE+ & $\begin{array}{l}\text { Use }+ \\
\text { (Descomposto em) }\end{array}$ & $\begin{array}{l}\text { Relação de } \\
\text { decomposição }\end{array}$ & $\begin{array}{l}\text { Relação entre um termo } \\
\text { composto não mais aceito e os } \\
\text { termos decorrentes da } \\
\text { decomposição. A relação } \\
\text { recíproca é UF+ }\end{array}$ \\
\hline
\end{tabular}

Tradução das siglas das relações semânticas, disponível originalmente em italiano na URL: $<$ http://thes.bncf.firenze.sbn.it/sigle.php?menuR=2\&menuS=2> 


\section{Conclusão: quanto Gesner é atual? Quanto é útil conhecer sua obra no presente documentário da web?}

Quando me perguntam qual é a atualidade do projeto bibliográfico gesneriano, respondo: o princípio do qual moveu, isso é: registrar o patrimônio escrito, classificá-lo, e identificar o que ainda era inédito, portanto ainda não público.

Não é isso o que continuamos fazendo nos cinco séculos seguintes? E não é o mesmo anseio que nos mobiliza hoje a nos interrogarmos sobre documentos, bibliotecas e arquivos digitais?

Como podemos recuperar aquilo que foi publicado em formato digital ou que é disponível digitalizado na web? Como podemos organizá-lo de forma classificada? Quais são os mapas científicos e documentários que podem nos nortear? Como podemos realizar na web uma busca semântica? Como podemos entender o que está presente e que ainda não?

Imaginemos o caos que a impressão impusera aos eruditos dos século XVI, e refletimos sobre o caos informacional atual: sobre a redundância de dados, a falta de um 'lugar exato' onde procurar, a necessidade de poder interrogar um sistema recebendo respostas pertinentes não de um ponto de vista linguístico, mas semântico, para não ter que abrir o caminho na web como em uma floresta a golpes de machado. A busca por palavras na web já é insuficiente porque, em função da quantidade de informações presentes, o usuário é obrigado a filtrar e interpretar os resultados, a presta atenção à sinonímia, a buscar, entre os resultados, respostas pertinentes por conteúdo. Eis que aquilo que procuramos são 'pandectae semanticas'!

Até hoje três tipos de busca são possíveis, ainda que não acessíveis a todos: a primeira é de tipo terminológico e com a linguagem term-based, típico da Information retrieval (IR); a segunda é de tipo semântico, desenvolvida principalmente pela linguagem dos linked data; por último, a de tipo semiótico pela linguagem content-based, experimentada pela Multimedia information retrieval (MIR).

A tipologia de busca que nesse contexto bibliográfico e documentário mais nos interessa é a segunda, ou seja, aquela de natureza semântica, que opera através das conexões corretas entre dados controlados na base, portanto certificados e des-diferenciados através de vocabulários, taxonomias, tesauros, ontologias gerenciadas por profissionais. As ontologias, 
Natureza e origem da Bibliografia: uma perspectiva disciplinar para contemporaneidade

em particular, estão se tornando fundamentais para limitar o overload informacional e para gerar um substrato catalográfico novo, predisposto para constituir a web.

Como sabemos, as bibliotecas e seu conteúdo informacional emergem raramente nos resultados dos motores de busca, tanto pela falta de aplicação da tecnologia informática que o torna possível, quanto porque até 5 ou 6 anos atrás se considerava necessário, talvez inconscientemente, separar a realidade bibliotecária do aspecto generalista da web. Se isso tinha ou não fundamento, agora é uma consideração sem mais valor, pelo menos pelo fato de que mesmo quem quer alcançar resposta de âmbito bibliográfico - portanto de pertinência bibliotecária - passa, em primeiro lugar, pela web, sendo já acostumado a uma tipologia de busca simplificada, imediata e de navegação e às respostas de sites comerciais de editores e livrarias antiquarias.

Os próprios OPACs são caros, considerando as tecnologias disponíveis e pouco eficazes face às expectativas dos leitores acostumados a percursos descobertos graças às relações entre as entidades. Portanto, os OPACs deverão ser readaptados também em relação à ordem dos elementos na interface de busca e dotados de requinte automático dos resultados. Trata-se de possibilidades que já existem mas que, no contexto bibliotecário, apresentam a urgência de serem aplicadas; e se as bibliotecas querem, de fato, continuar a ser parte da vida cotidiana da sociedade, devem poder 'penetrar' na web, invadir a curiosidade dos cibernautas e se impor ao seu dia-a-dia heurístico.

Voltemos à tecnologia dos linked data, destinada a ser um dos atores dessa mudança desejada. As bibliotecas, como as outras instituições culturais representadas por arquivos e museus, devem começar a trabalhar nessa perspectiva, utilizando as inúmeras ontologias especializadas: por exemplo aquelas para a descrição bibliográfica e arquivística (ISBD, FRBR, RDA, OAD), para aquela dos elementos de autoridade (FRAD, FRSAD, LCSH), dos lugares geográficos (GeoNames e FAO Geopolitical Ontologies), dos vários direitos (Creative Commons Rights Expression Language), para as citações (BIBO, SPAR), para os metadados de preservação, para os metadados de dataset etc.

As ricas possibilidades metodológicas e de repertório que a tecnologia oferece e das quais oferecemos exemplos permitem constatar como os momentos críticos para a documentação são aqueles impostos pelo aparecimento das novas tecnologias, que nascem sempre como resposta à necessidade de aumentar o número de pessoas alcançadas, procurando eliminar os obstáculos do tempo e do espaço. Obtido o instrumento, realizada a 
possibilidade, aparece a necessidade de dominar os excessos e o caos que as novas situações geram. A procura de uma organização todas às vezes apresenta as mesmas premissas, as mesmas finalidades e as mesmas lógicas humanas aplicadas.

Gesner é, portanto, atual. Aliás, diria extraordinariamente atual. Com as devidas proporções de complexidade gerencial, o que somente ele conseguiu nem sempre os nossos inúmeros grupos de trabalho e de pesquisa conseguem tão bem hoje. Dominar a informação, organizar o conhecimento, chegar a uma "ecologia informacional" é, nesse momento, a maior necessidade e o âmbito mais ocupado das mentes de nossa área. Talvez poderá ajudar, com efeito, a possibilidade de reutilizar dados e a filosofia de responsabilidade cultural proposta pelo padrão de conteúdo RDA (Resource Description and Access) com o auxílio da tecnologia dos Linked data. Essas linhas mestras e aquela tecnologia podem se tornar a chave para a constituição de uma web já comumente chamada semântica, ainda que talvez de forma um pouco apressada, no sentido em que as relações estabelecidas entre os elementos descritivos dos documentos (isso é, dos dados fornecidos de forma completa, exaustiva e identificativo/des-diferencial) serão certificados, oportunos, côngruos no significado e não casuais. A web semântica corresponderá assim ao ambiente em que os recursos publicados são associados a informações e metadados que especificam seu contexto semântico em um formato adapto à elaboração (busca) automática. As máquinas poderão, assim, acessar um conjunto estruturado de informações que lhes permite reutilizar os dados em novas formas, baseadas em regras de inferência.

Nesse contexto, as bibliotecas terão, ainda, seu papel no campo da ciência e da informação documentária enquanto instituições culturais que, com os arquivos e os museus, deverão ocupar-se da preservação e sistematização do patrimônio cultural, tornando possível e fácil a visão e o acesso, o gozo público tanto estético quanto científico. Essa participação será fundamental porque se oporá à massa informacional descontrolada da web, superficial e não confiável, bem como caótica e desorganizada que, portanto, deixa submersa e dispersada boa parte das informações e documentos relevantes e qualificados.

Concluindo: a Bibliografia não é somente uma disciplina e uma ciência, mas também uma filosofia para a abordagem responsável, consciente e estruturada ao universo dos documentos, para garantir a permanência da civilização.

A Bibliografia, através das bibliotecas, afirmará novamente sua missão em um futuro aparentemente distante do passado no qual colocamos Gesner mas - talvez, como o próprio 
Gesner consideraria conforme a visão de zwingliana que o animava - em um futuro que com o passado e o presente são um momento único da humanidade.

\section{Referências}

\section{Para aprofundar sobre a epistemologia da Bibliografia}

BERNSTEIN, Lawrence F. The bibliography of music in Conrad Gesner's Pandectae (1548). Acta Musicologica, v. 45, fasc. 1, jan./jun.1973. pp. 119-163. Disponível em:

<http://www.jstor.org/stable/932225>. Acesso em: 15 maio 2015.

BLAIR, Ann. Reading strategies for coping with information overload ca.1550-1700. Journal of the history of ideas, v. 64, n. 1, p.11-28, 2003.

EADEM. Un clamoroso plagio bibliografico alla metà del cinquecento. Bibliotheca, v. 4, n. 1, p. 279-285, 2005.

JASENAS, Michael. A history of the bibliography of philosophy. New York; Georg Olms verlag Hildesheim. 1973.

NELLES, Paul. Reading and memory in the universal library: Conrad Gesner and the renaissance book. In: BEECHER, Donald; WILLIAMS, Grant (ed.). Ars reminiscendi: mind and memory in Renaissance culture. Toronto: Centre for Reformation and Renaissance Studies, 2009.

ROSENBERG, Daniel. Early Modern Information Overload. Journal of the History of Ideas, v. 64, n. 1, p. 1-9, January 2003.

SABBA, Fiammetta. "Documenti" e "Monumenti": un contributo alla epistemologia bibliografica. Accademie e Biblioteche d'Italia, v. 3/4, p. 11-19, 2004.

Indici bibliografici. Bibliotheca, v. 5, n. 1, p.78-86, 2006.

SABBA, Fiammetta (Ed.). Le biblioteche private come paradigma bibliográfico: atti del Convegno Internazionale, Roma, Tempio di Ariano, 10-12 ottobre 2007. Roma: Bulzoni, 2008. 524 p. (Il Bibliotecario, 20).

Introduzione. In: MINISTERO PER I BENI E LE ATTIVITÀ CULTURALI BIBLIOTECA ANGELICA. Indice dei nomi degli Autori dei manoscritti in scrittura latina della Biblioteca Angelica di Roma. Roma: Istituto Poligrafico e Zecca dello Stato, Libreria dello Stato, 2009. (Collezione "Indici e Cataloghi").

SERRAI, Alfredo. Analecta libraria: temi di critica bibliografica e di storia bibliotecaria. Roma: Bulzoni, 2000. 
Fiammetta Sabba

Biblioteconomia come scienza: introduzione ai problemi e alla metodologia.

Firenze: Olschki, 1973.

Breve storia delle biblioteche in Italia. Milano: Sylvestre Bonnard, 2006.

Le classificazioni: idee e materiali per una teoria e per una storia. Firenze:

Olschki, 1977.

Il cimento della bibliografia. Milano: S. Bonnard, 2001.

Dai loci communes alla bibliometria. Roma: Bulzoni, 1984.

Flosculi bibliographici. Roma: Bulzoni, 2001.

Guida alla biblioteconomia. Firenze: Sansoni, 1983.

Dalla informazione alla bibliografia: la professione bibliotecaria. Milano:

Bibliografica. 1984.

Natura elementi e origine della bibliografia in quanto mappa del sapere e delle lettere. Roma: Bulzoni, 2010.

Ricerche di biblioteconomia e di bibliografia. Firenze: La nuova Italia, 1983.

. Storia della bibliografia: Roma: Bulzoni, 1988-2011. (11 volumes em 13 tomos:

I-IX; X/1-2; XI/1-2): 1. Bibliografia e Cabala; Le enciclopedie rinascimentali (1). - 2. Le enciclopedie rinascimentali (2); Bibliografi universali. - 3. Vicende e ammaestramenti della 'Historia literaria'. - 4. Cataloghi a stampa; Bibliografie teologiche; Bibliografie filosofiche; A. Possevino. - 5. Trattatistica biblioteconomica. - 6. La maturità disciplinare. - 7. Storia e critica della catalogazione bibliografica / a cura di Gabriella Miggiano. - 8. Sistemi e tassonomie / a cura di Marco Menato. - 9. Manualistica, didattica e riforme nel sec. XVIII. 10/I-II. Specializzazione e pragmatismo: i nuovi cardini della attività bibliografica. - 11/I-II. Indici volumi I-X.

SERRAI, Alfredo; SABBA, Fiammetta. Profilo di Storia della bibliografia. Milano: Edizioni Sylvestre Bonnard, 2005.

* Numerosos artigos e intervenções nos periódicos bibliográficos: «Il Bibliotecario», Roma, Bulzoni Editore (1984-1999, 2008-2011); «Bibliotheca, Rivista di studi bibliografici» Milano, Sylvestre Bonnard (2002-2007); «Bibliothecae.it» Perugia, Morlacchi Editore (2012-2015, e em 2016 é publicado in open access na plataforma ALMA DL da Alma Mater Studiorum di Bologna. 


\section{Para aprofundar sobre Conrad Gesner}

CANFORA, Luciano. Il Fozio ritrovato: Juan de Mariana e André Schott. Con l'inedita Epitome della Biblioteca di Fozio ed una raccolta di documenti a cura di Giuseppe Solaro. Appendici di Renata Roncali, Niccolò Zorzi, Margherita Losacco, Luciano Canfora. Bari: Edizioni Dedalo, 2001.

CECCARELLI, Maria Grazia. il fondo "Tigurino" della Biblioteca Passionei all'Angelica. Il Bibliotecario, v. 9, p. 93-132, 1986.

COCHETTI, Maria. Repertori bibliografici del cinquecento. Roma: Bulzoni, 1987.

DAVIS, Margaret Daly. Conrad Gesner: Pandectarum, sive Partitionum universalium ... libri XXI (Zürich 1548). Auszüge zur Kunstgeschichte und Altertumswissenschaft / Excerpted bibliographies for the history of art and the study of antiquity. Fontes. Quellen und Dockumente zur Kunst 1350-1750. (1 nov. 2007). Disponível em: <http://archiv.ub.uniheidelberg.de/artdok/378/1/Daly_Davis_Fontes1.pdf>

FISCHER, Hans; PETIT, Georges, STAEDTKE, Joachim, STEIGER, Rudolf, ZOLLER, Heinrich. Conrad Gessner, 1516-1565: Universalgelehrter, Naturforscher, Arzt. Zürich, 1967.

FRYDE, Edmund B. Humanism and Renaissance Historiography. London: Hambledon Press, 1983.

GERMANN, Martin. Die reformierte Stiftsbibliothek am Grossmünster Zürich im 1. Jahrhundert und die Anfänge der neuzeitlichen Bibliographie. Rekonstruktion des Buchbestandes und seiner Herkunft, der Bücheraufstellung un des Bibliotheksraumes. Mit Edition des Inventars 1532/1551 von Conrad Pellikan. Wiesbaden: Harrassowitz, 1994.

HANHART, Johannes. Conrad Gessner. Ein Beytrag zur Geschichte des wissenschaftlichen Strebens und der Glaubensverbesserung im 16ten Jahrhundert. Winterthur: in der Steinerischen Buchhandlung, 1824.

HARTMANN, Alfred; JENNY, Beat Rudolf. Die Amerbachkorrespondenz. VI. Band. Die Briefe aus den Jahren 1544-1547. Basel: Verlag der Universitätbibliothek, 1967.

HOBSON, Anthony. The "Iter Italicum" of Jean Matal. In: STUDIES in the book trade in honour of Graham Pollard. Oxford: Oxford Bibliographical Society, 1975. p. 33-61. (Oxford Bibliographical Society Publications, 18.).

HOBSON, Anthony. Renaissance book collecting: Jean Grolier and Diego Hurtado de Mendoza, their books and bindings. Cambridge, University Press: 1999.

IRIGOIN, Jean. Les ambassadeurs a Venise et le commerce des manuscrits grecs dans le années 1540-1550. In: BECK, Hans-Georg; MANOUSSACAS Manoussos, PERTUSI, Agostino. Venezia centro di mediazione tra Oriente e Occidente (secoli XV-XVI): aspetti e problemi. Firenze: Leo S. Olschki, 1977. V. 2. p.399-415. 
JENNY, Beat Rudolf. Arlenius in Basel. Basler Zeitschrift für Geschichte und Altertumskunde, 64 (1964), p. 5-45.

LEU, Urs B. Conrad Gesner als theologe: ein Beitrag zur Zürcher Geistesgeschiochte des 16. Jahrhunderts. Bern: P. Lang, 1990.

LEU, Urs B.; KELLER, Raffael; WEIDWANN, Sandra. Conrad Gessner's private library. Leiden-Boston: Brill, 2008.

SABBA, Fiammmeta. La Biblioteca di Diego Hurtado de Mendoza nella "Bibliotheca Universalis" di Conrad Gesner. Bibliotheca, v. 6, n. 2, p. 93-112, 2007.

La 'Bibliotheca Universalis' di Conrad Gesner: monumento della cultura europea. Roma: Bulzoni, 2012.

Gli scrittori italiani di Medicina nella 'Bibliotheca Universalis' di Conrad Gesner", Bibliologia, v. 8, p. 39-62, 2013.

SERRAI, Alfredo. Conrad Gesner. Roma: Bulzoni, 1990.

. Domenico Passionei e la sua Biblioteca. Milano: Sylvestre Bonnard, 2004.

. I 'Pandectae' di Conrad Gesner. Bibliotheca, v. 1, p. 11-37, 2007.

. Una scoperta sensazionale all'Angelica: da Gesner a Passionei e

Scheuchzer. Il Bibliotecario, v. 7/8, p. 81-103, 1986.

STEIGER, Rudolf. Erschließung des Conrad-Geßner-Materials der Zentralbibliothek Zürich, Gessnerus, v. 25, p. 29-64, 1968.

WELLISH, Hans. Conrad Gessner: a bio-bibliography. Zürich, 1984.

Alguns títulos de autores italianos para aprofundar os temas tratados ligados à contemporaneidade catalográfica e da information retrieval

BIAGETTI, Maria Teresa. Nuove funzionalità degli OPAC e relevance ranking. Bollettino AIB, v. 50, n. 4, p. 339-356, 2010.

. Sviluppi e trasformazioni delle biblioteche digitali: dai repositories di testi alle semantic digital libraries. AIB studi, v. 54, n. 1, p. 11-34, 2014. DOI: 10.2426/aibstudi-9955. gennaio/aprile

BIANCHINI, Carlo; GUERRINI, Mauro. Introduzione a RDA. Milano: Bibliografica, 2014. [Recensione di Fiammetta Sabba: Bibliothecae.it. Rivista semestrale di studi, v. 3, n. 2, p. 239-240, 2014] 
GUERRINI, Mauro; POSSEMATO, Tiziana. Linked data per biblioteche, archivi e musei. Milano: Editrice Bibliografica, 2015 [Recensione di Fiammetta Sabba: Bibliothecae.it. Rivista semestrale di studi, v. 5, n. 1, 2016. No prelo].

RAIELI, Roberto; INNOCENTI, PERLA (Ed.). Multimedia information retrieval: metodologie ed esperienze internazionali di content-based retrieval per l'informazione $e$ la documentazione. Premissa di Lucia Mafferi. Roma: AIDA, 2004.

RAIELI, Roberto. Così lontani, così vicini: i possibili alleati delle biblioteche nelle sfide per la trasmissione delle conoscenze. AIB studi, v. 53, n. 1, p.5-8, 2013.

Multimedia Digital Libraries Handling: the Organic MMIR Perspective, in Bridging between Cultural Heritage Institutions. In: ITALIAN RESEARCH CONFERENCE ON DIGITAL LIBRARIES, 9., 2013. Proceedings... BerlinHeidelberg: Springer, 2014. p. 171-186. v. 385.

2013.

. Multimedia Information Retrieval: theory and techniques. Oxford: Chandos,

Nuovi metodi di gestione dei documenti multimediali: principi e pratica del MultiMedia Information Retrieval. Milano: Bibliografica, 2010.

. The semantic hole: enthusiasm and caution around the MultiMedia Information Retrieval, Knowledge Organization, v. 39, n. 1, p.13-22, 2012.

SABBA, Fiammetta. Il digitale deve confrontarsi con la Bibliografia. Bibliothecae.it., v. 2, n. 1, p. 281-289, 2013.

La Biblioteca digitale tra risorsa e aspirazione del bibliografo. Atti del Convegno

'Noetica versus informatica': le nuove strutture della conoscenza scientifica' (19-20 novembre 2013). Roma-Firenze, CCIAA-Olschki, 2015. p. 217-229 (più 'Nota del curatore' a p. XI).

Cantiere documentazione. Bibliothecae.it, v. 4, n. 1, p.147-161, 2015.

SABBA, Fiammetta (Ed.). Noetica versus informatica: le nuove strutture della comunicazione scientifica. Atti del convegno internazionale, 19-20 novembre 2013. Firenze: Leo S. Olschki, 2015. 